\title{
REVIEW \\ Why are individuals so different from each other?
}

\author{
P Bateson
}

An important contributor to the differences between individuals derives from their plasticity. Such plasticity is widespread in organisms from the simple to the most complex. Adaptability plasticity enables the organism to cope with a novel challenge not previously encountered by its ancestors. Conditional plasticity appears to have evolved from repeated challenges from the environment so that the organism responds in a particular manner to the environment in which it finds itself. The resulting phenotypic variation can be triggered during development in a variety of ways, some mediated through the parent's phenotype. Sometimes the organism copes in suboptimal conditions trading off reproductive success against survival. Whatever the adaptedness of the phenotype, each of the many types of plasticity demonstrates how a given genotype will express itself differently in different environmental conditions - a field of biology referred to as the study of epigenetics. The ways in which epigenetic mechanisms may have evolved are discussed, as are the potential impacts on the evolution of their descendants. Heredity (2015) 115, 285-292; doi:10.1038/hdy.2014.103; published online 19 November 2014

\section{INTRODUCTION}

Many differences between individuals are undoubtedly because of differences in their genes. However, human monozygotic twins who are genetically identical may differ markedly from each other (Spector, 2012). Individuals differ, of course, because biological processes are inherently variable. Even so, environmentally induced variation is such that understanding the mechanisms underlying plasticity has moved to centre stage of current research.

The term 'plasticity' refers to the changeable character of matter. It is used in physics for inanimate materials and in that field it is contrasted with 'elasticity'. If a coiled spring is pulled beyond the limits of elasticity, it will be permanently elongated. Provided that the spring does not break, the change is plastic. In the nineteenth century, the term was introduced into medicine to refer to the renewal of injured tissue and into popular literature to refer to impressionable minds. Behavioural plasticity was a dominant theme of Baldwin's (1902) book. It has returned in many other works about behaviour and the nervous system (for example, Horn et al., 1973; Gollin, 1981; Lerner, 1984; Rauschecker and Marler, 1987). The growth of knowledge about plasticity at all levels of analysis has been astonishing. The number of papers dealing with plasticity of all types and in all sciences was listed in the Web of Science as 52 in 1970, 299 in 1980, 1354 in 1990, 13157 in 2000 and 27826 in 2010 alone. And the numbers published in each year rise at an ever-increasing rate.

Nowadays, plasticity, defined broadly in terms of malleability (see Pigliucci, 2001) is applied widely in biology with the literature on plasticity in animals diversifying rapidly. In 2011, Neurosciences and Behaviour Reviews carried 12 contributions on resilience, namely the different ways in which animals respond to stress and why they should do so. In 2012, Integrative and Comparative Biology included 10 essays on various aspects of the impact of plasticity on evolution (see Wund, 2012). Kappeler et al. (2013) introduced and summarised a themed issue in the Philosophical Transactions of the Royal Society on flexibility and constraint in the evolution of mammalian social behaviour with 13 contributions. They emphasised how variation in the components of social systems can depend on the mating system and on social organisation. In a special section of Animal Behaviour, Foster and Sih (2013) introduced 12 contributions on behavioural plasticity and evolution with an excellent overview by Snell-Rood (2013) and with several contributors examining animals' responses to marked changes in habitats induced by humans. In my book with Peter Gluckman, we also reviewed the plasticity literature and discussed the many different forms of plasticity, how they might have evolved and how they might affect subsequent evolution (Bateson and Gluckman, 2011). Strikingly, all these extensive and varied contributions to the subject of biological plasticity overlap relatively little in terms of the scientific literature that they cover. Anybody who wants to be completely up-to-date has a lot of reading to do in the behavioural field alone.

In this article, I shall not go over ground that I have covered in detail in previous publications (for example, Bateson, 2012, 2014). I shall however consider briefly the plastic mechanisms that enable an organism to cope with a novel challenge not previously encountered by the organism's ancestors. I shall refer to them collectively as 'adaptability plasticity'. I shall then consider mechanisms that appear to have evolved from repeated challenges from the environment. They do so by responding in a conditional manner so that if the environment is $\mathrm{A}$, the organism gives response $\mathrm{X}$, and if it is $\mathrm{B}$, the organism gives response Z. I shall refer to them collectively as 'conditional plasticity'.

\section{ADAPTABILITY PLASTICITY}

Accommodating to disruption of normal development

An individual whose body has been damaged in an accident or who is burdened with a mutation that renders its body radically different from other individuals may be able to accommodate to such abnormality (West-Eberhard, 2003). In doing so, the individual may 
develop novel structures and behaviour not seen in other individuals of the same species. Such accommodation can be particularly marked when it occurs early in development. A goat (Capra aegagrus hircus) born without forelimbs walked about on its hind legs and developed a peculiar musculature and skeleton (Slijper, 1942). A modern instance is the bipedal domestic dog, Faith, whose remarkable ability can be viewed on YouTube http://www.youtube.com/watch? $\mathrm{v}=5 \mathrm{QKG} 3 \mathrm{CKZTU}$. The animals have coped with an abnormality by accommodating to it, producing coordinated changes in functionally related characters. Similarly, humans born with limb abnormalities as a result of exposure to a teratogen such as thalidomide develop strategies to cope, for example, by handling objects using their feet or teeth in ways for which others might use their hands (von Moltke and Olbing, 1989).

The capacity of the individual to respond to neural damage is remarkable particularly when the damage occurs early in life (Bateson and Gluckman, 2011). In such cases, the brain reorganises and morphologically can look markedly different from the brain of a normal individual. Even so, the effects on behaviour may be scarcely detectable and the plasticity at the neural level may be accompanied by robust development at the behavioural level.

Another form of 'coping', found especially during early development, arises when the organism must make immediate responses to survive a challenge but, in contrast to accommodation responses, the normal developmental sequence is not necessarily disrupted. Although these responses may involve either structural or temporal changes in the course of development, in contrast to phenotypic accommodation, they do not entail a fundamental change in the normal pattern of development. Thus, the phenotypic consequences are not as marked as those that involve accommodation, but may have a cost and become disadvantageous to the individual later in life (Gluckman et al., 2005).

If the mother is undernourished or if the placenta is not delivering optimal nutrition, the offspring may be born smaller than usual, with the consequences of greater infant mortality and lower fitness in later life resulting from persistent growth failure (Gluckman et al., 2005). In polygynous species, such as red deer (Cervus elaphus), the fitness costs may be severe because a small male is less able to compete with larger males for mates and, as a consequence, has a much lower chance of fathering offspring. Nevertheless, survival means that the small male does have some possibilities for mating unobtrusively when larger males are not looking (Kruuk et al., 1999). In humans, growth retardation following placental insufficiency may be associated with reduced muscle mass, bone density, adult size, and cognitive and attentive function. These neurological effects may be related to a tradeoff between investing for the long term in neural capacity and the need to expend the limited energetic supply for immediate survival (Gluckman and Hanson, 2006).

\section{Rapid modification of behaviour}

One of the most primitive changes in behaviour in response to experience is nonspecific. Sensitisation usually results from exposure to an alarming stimulus (such as a blow-up toy snake suddenly becoming inflated), which elicits a variety of defensive or aversive reactions from the animal. Subsequently, many other potentially aversive stimuli (such as loud sounds) will have the same effect even though this would not have been the case had the animal not been previously sensitised.

Thorpe (1956) classified learning into five categories: habituation, classical conditioning, instrumental conditioning, latent learning and insight learning. Some forms of learning such as behavioural imprinting, which Thorpe discussed in his chapter on insight learning, and the acquisition of song in birds may be restricted to early development, but most can take place throughout life.

Habituation is defined as a decrease in response occurring as the result of prolonged stimulation, which cannot be attributed to fatigue or sensory adaptation. The phenomenon has been described widely from single-celled organisms to humans. In some cases, the underlying process is simple, and in other cases, the experiments suggest that the subject establishes a specific representation of the stimulus in its nervous system. Establishing a neural representation is key to the form of learning that leads to a categorisation of the sensory world. Here again such perceptual learning is found widely across the animal kingdom. In humans, it leads to the recognition of faces and places. The ability to distinguish between the vast array of objects, people and scenes experienced in a lifetime is of inestimable value and happens simply as a result of exposure.

Pavlovian (or classical) conditioning allows the individual to predict what will be of real significance in the confusing world of sights, sounds and smells. Pavlov's famous experiment was to teach a dog to expect food by repeatedly alerting it with a buzzer before the food was presented. A different form of associative learning enables the organism to control the environment. If a rat presses a bar and its action is swiftly followed by the delivery of food, it will repeat the action and will do so with increasing frequency if each time the action elicits the reward and then it may be repeated many times even in the absence of the reward (or 'reinforcer'). The so-called cognitive revolution in the study of behaviour has undoubtedly greatly enriched the toolbox for understanding learning processes and is very well summarised by Shettleworth (2010).

\section{Immunological plasticity}

In the immune system of humans and vertebrate animals, molecular plasticity takes the form of generating new antibodies to foreign proteins that hitherto have not been encountered by the individual. Antibodies are immunoglobulins used by the immune system to identify and neutralise foreign pathogens such as bacteria and viruses, preventing them from causing disease. The plasticity of the immune system involves selection rather than instruction as, by extremely rapid mutation and recombination, the immune system finds a match for the foreign antigen and this then sets in train rapid synthesis of the antibody from the mutated gene that provided the match. The gene has been selected by the challenge from outside the host's body.

\section{CONDITIONAL PLASTICITY}

Responses to predation or variation in food resources have provided some of the best examples of conditional responses to local environmental conditions. The conditional response may be dichotomous or it may be graded so that it is proportional to the degree of the challenge providing what is termed 'the norm of reaction'. Some plastic responses induced in early life may have delayed benefits, so that their primary or only adaptation is expressed at a much later stage in the life cycle. Such anticipatory responses rely on a cue in early life predicting some characteristic of the future environment. The implication of many such examples is that environmental induction provides a forecast about the conditions of the world that the individual will subsequently inhabit (Bateson, 2001). In mammals, the best route for such a forecast may be via the mother. Vole pups (Microtus pennsylvanicus) born in the autumn have thicker coats than those born in spring; the cue to produce a thicker coat is provided by hormonal signals from the mother before birth (Lee and Zucker, 1988). The potential benefit of doing so was termed the predictive adaptive response by Gluckman and Hanson (2006). 
Nutrition during development may affect the individual's preparedness for the nutritional environment when it is adult. Saastamoinen et al. (2010) found that undernourished larvae of an East African butterfly (Bicyclus anynana) had more strongly developed thoracic musculature after pupation, enabling them to fly more strongly as adults and potentially to reach more favourable environments. When pregnant mother rats (Rattus norvegicus) were given restricted diets, their offspring were smaller when they were born, but if these offspring were then given plentiful food they became much more obese than the offspring of mothers given an unrestricted diet (Jones and Friedman, 1982). This observation was followed by further extensive work on rats in many laboratories. Offspring born to undernourished rats developed increased appetites (Vickers et al., 2000). Even though the undernourished rats are more sedentary when kept in standard laboratory cages (Vickers et al., 2003), their behaviour differs in another striking way from the control animals. When given a choice between pressing a lever to obtain food and running in a wheel, they are significantly more likely to run in the wheel (Miles et al., 2009). This finding suggests that these offspring of undernourished mothers may attempt to find more reliable sources of food in a natural environment.

In human biology extensive studies of the effects of maternal nutrition on the offspring's outcome characteristics have shown how maternal condition affects body composition, metabolic control, neuronal reserve, kidney size, reproductive maturation and behaviour (McMillen and Robinson, 2005). Human children with lower birth weights are likely to enter puberty early (Sloboda et al., 2007), birth weight being taken to be a proxy for poor intrauterine nutrition. The individual relatively undernourished in early life has a preference for high-fat foods, a higher set-point for satiety and a smaller somatic phenotype-a suite of characteristics that well are adapted to limited food resources in adult life. If human foetuses respond to nutritional cues provided by their mothers, then those individuals who experience cues that indicate a plentiful environment should be adversely affected if they encounter famine later in life. Indeed, the evidence suggests that people who enjoyed a plentiful environment in early life may be at greater risk during periods of prolonged famine than those who experienced relatively lower levels of nutrition in utero. In concentration camps and the worst prisoner-of-war camps, many reports have indicated that the physically large individuals died first while at least some of the small individuals survived (Bateson, 2001). In an Ethiopian population suffering from famine, high birth weight of babies who had had mothers on a higher plane of nutrition was associated with a ninefold higher risk of rickets, which carries fitness costs during reproduction, particularly for women (Chali et al., 1998). Children born smaller are less likely, in a famine, to develop kwashiorkor, the form of infant malnutrition with high mortality that involves a lower ability to mobilise substrates. In contrast, the lowbirth-weight children respond to severe undernutrition by developing marasmus, which is associated with much lower mortality (Jahoor et al., 2008).

Maternal forecasting by induction of a specific developmental trajectory is thought by many researchers to be important in human biology (for example, Bateson, 2001; Gluckman and Hanson, 2004; Sandman et al., 2012). The individual benefits, it is argued, by adjusting the trajectory of his or her development so that the developed phenotype is most likely to match the anticipated environment. In general, a cue from the mother suggesting a future environment with relatively scarce resources leads to a more economical body form and a bias towards insulin resistance, thereby capturing the higher-energy fat-dense foods when they are available (Gluckman et al., 2010). A full discussion of the predictive adaptive response in humans is provided elsewhere (Bateson et al., 2014). Although the evidence provides strong grounds for supposing that humans exhibit conditional plasticity, extreme nutritional impoverishment of the mother can have long-term effects that are maladaptive (Gluckman and Hanson, 2004).

\section{MANY PROCESSES INVOLVED IN PLASTICITY}

Plasticity takes many different forms. I have discussed the differences between mechanisms that express adaptability and those that respond conditionally to external cues, Snell-Rood (2013) distinguished between 'developmental plasticity' occurring in early life and what she called 'activational plasticity' by which an individual can change its characteristics throughout life (see also Piersma and van Gils, 2010). When a process occurs early in development but not later, it is often referred to as occurring in a 'sensitive period' (see Bateson and Gluckman, 2011). The processes involved in the start of a sensitive period generally correspond with changes in the ecology of the developing individual. These changes are linked to developmental processes of regulation and cellular replication. The processes that bring the sensitive period to an end may reflect the passage of normal growth and temporal constraints on development in other related processes. Sometimes the terminating processes are related to the gathering of crucial information and, except in extreme circumstances, do not shut down until that information has been gathered. In these cases, the ending of the sensitive period reflects the variable opportunities for gathering such domain-specific information in the real world. For example, in cold weather, ducks brood their hatched young for longer than in warm weather, and the ducklings delay the process of learning the characteristics of their mother (Bateson and Martin, 1999). A limit must be set on such flexibility, however, because so much else has to be done in development. If the relevant information remains unavailable for too long, the individual may eventually have to settle for less than the best and develop without acquiring that information.

Snell-Rood's (2013) category of activational plasticity might be thought to apply to all classes of learning but behavioural imprinting is associated with sensitive periods in development. It is the process by which a young animal rapidly learns the details of its mother's individual appearance and forms a social attachment to her (Lorenz, 1935; Bateson, 1966; Bolhuis, 1991). A distinction is drawn between filial imprinting and sexual imprinting, whereby the animal's experience later in life affects its sexual preferences. These sexual preferences are for partners that are slightly different from those individuals (usually close kin in natural conditions) with which the animal is already familiar (Bateson, 1983). Although the preferences are generally robust, they can change under special conditions such as those associated with high levels of stress (Bateson and Martin, 1999).

The acquisition of songs by birds also starts early in life. The typical pattern is for the young male bird to listen to and memorise sounds made by his father and other males during the first few months after he has hatched. The following spring he produces a range of sounds and, by degrees, settles on songs he has heard before. When he is mature, he uses his songs to defend his territory and attract females. Although avian song-learning often occurs early in development and is irreversible, in some species such as the canary (Serinus canaria), the repertoire changes in each breeding season, and in others, such as the European blackbird (Turdus merula), it is added to each season (Marler and Slabberkoorn, 2004).

Examples of plasticity include coping with disruption of normal development, different phenotypic outcomes generated by different 
cues early in development, learning and the plasticity found in the nervous and the immune systems. A key question is whether these vastly heterogeneous phenomena have anything in common with each other. Plasticity operating at different levels of organisation often represents different descriptions of the same process. Underlying behavioural plasticity is neural plasticity, and underlying that is the molecular plasticity. The plasticity of the immune system, with its long-lasting effects similar to memory, relies on a selective process in development. In contrast, at the level of the whole organism, the processes of learning that change behaviour seem to involve instruction. Whether the same selective process could be involved in any or all of the myriad examples of learning is, however, much more controversial. In the case of associative learning, for example, a cue from the environment instructs the individual about the causal nature of its environment, providing a link between something that is biologically significant and something that had hitherto been neutral. As yet, the underlying mechanism involving changes in neural connectivity is not readily attributable to a process that involves selection. That said, the process of strengthening (reinforcement) of one of many different possible actions has often been likened to the Darwinian process of variation, differential survival and inheritance in evolution (Skinner, 1984; Snell-Rood, 2012; Heisenberg, 2013).

An underlying selection mechanism, similar to that of the immune response, might fit better with the examples of conditional plasticity, whereby the genome is capable of giving rise to a variety of phenotypes depending on the individual's experience. In many cases of conditional plasticity that abound across the animal and plant kingdoms, the individual starts its life with the capacity to develop in a number of distinctly different ways. The individual has the potential to express a phenotype that is adaptive in the appropriate context. The particular phenotype is triggered by a feature of the environment in its environment-whether it is the odour of its predators, the available quality of food or the presence of other males.

Whether or not the numerous examples of plasticity are necessarily or even plausibly related, they are all of great biological and psychological significance even when they refer to pathologies. Plasticity can be viewed in many ways and along many different dimensions. The temporal dimension, the dimension of different organisational levels, the mechanistic dimension of whether plasticity involves selection or instruction and the functional and evolutionary issues are all part of the picture. A multidimensional view is essential if the ways in which the organism responds to environmental cues and challenges are to be understood. However, the understanding needs to be broadened to take account of the ways in which plasticity is constrained and regulated.

\section{EPIGENETICS}

A substantial body of evidence indicates, then, that individuals of the same species, the same age and the same sex may differ strikingly in their phenotypes. The developmental processes involved were subsumed under the general heading of 'epigenetics' by Waddington (1957). He distinguished this term from the eighteenth century term 'epigenesis', which had been used to oppose the notion that all the characteristics of the adult were preformed in the embryo. More recently, epigenetics has become mechanistically defined as the molecular processes by which traits defined by a given profile of gene expression can persist across mitotic cell divisions, but which do not involve changes in the nucleotide sequence of the DNA (Carey, 2012). Developmental biology had already paved the way for understanding what is an obvious feature of ontogeny. While all cells within the body of a multicellular organism contain the same genetic sequence information, each lineage has undergone specialisations to become a skin cell, hair cell, heart cell and so forth. These phenotypic differences are inherited from mother cells to daughter cells. The process of differentiation involves the expression of particular genes for each cell type in response to cues from neighbouring cells and from the extracellular environment, and the suppression of others. Genes that have been silenced at an earlier stage remain silent after each cell division. Such control of gene expression provides each cell lineage with its specific characteristic. As these epigenetic marks are faithfully duplicated across cell division, stable cell differentiation results.

The general principles of differentiation apply at higher levels of organisation and are involved in mediating many aspects of developmental plasticity seen in intact organisms. For that reason, some authors (for example, Jablonka and Lamb, 2010) and most developmentally inclined ethologists like myself (Bateson, 2012) continue to use Waddington's broader definition of epigenetics to describe all the developmental processes that bear on the character of the organism.

The processes involved in gene expression and suppression can be transmitted from one generation to the next. Before this was demonstrated, it was already apparent that extragenetic inheritance processes are important in inheritance. These include cytoplasmic effects, parental effects, ecological legacies, behavioural traditions and cultural inheritance (Mousseau and Fox, 1998; Odling-Smee et al., 2003; Jablonka and Lamb, 2005; Gilbert and Epel, 2009; Danchin et al., 2011). Many of the factors that influence individual development, be they social or ecological, have been amassed by the activities of multiple individuals over multiple generations (cultural knowledge, ecological legacies). Some of these influences on development may stretch back a long way in time. The presence of animal burrows, moundsand dams - or, on a larger scale, changed atmospheric states, soil states, substrate states, or sea acidity (Meysman et al., 2006; Erwin, 2008) — persist or accumulate in environments, and can be crucial for normal development.

The evidence for transmission of the epigenome across generations in both animals and plants is substantial (Gissis and Jablonka, 2011). After mother rats had been injected with an endocrine disruptor, lowered spermatogenic capacity and several adult-onset diseases were observed over four successive generations in their male descendants. These effects were accompanied by altered DNA methylation patterns in the germline (Anway et al., 2005; Jirtle and Skinner, 2007; Stouder and Paoloni-Giacobino, 2010). In the plant Arabidopsis, epigenetic inheritance can occur over at least eight generations (Johannes et al., 2009; Cortijo et al., 2014). In the nematode worm Caenorhabditis elegans, stable transmission across generations depends on gene regulation by microRNA (Rechavi, 2014). Rassoulzadegan (2011) found that injection of RNA from sperm from one strain of mice into wild-type embryos led to a distinct phenotype in the offspring, which was in turn transmitted to their progeny. Mouse embryos injected with a microRNA that targets an important regulator of cardiac growth developed hypertrophy of the cardiac muscle, which was passed on to descendants through at least three generations without loss of effect (Wagner et al., 2007).

\section{HOW DID PLASTICITY EVOLVE?}

The costs of evolving plastic processes are not known, even though the costs of maintaining them are likely to be low (van Buskirk and Steiner, 2009). Plasticity is conserved across all multicellular taxa (Bateson and Gluckman, 2011). Given that evolutionary change in response to Darwinian evolution can be rapid, this suggests that a fitness advantage exists to sustaining plasticity in some aspects such as 
those affected by normal variation in levels of nutrition, predation and stress.

Adaptability plasticity may confer the potential to cope with a wider range of environments than would otherwise be possible, and also to sustain fitness when environmental conditions fluctuate, particularly when the environment changes relatively slowly. Sultan et al. (2009) studied two ecologically distinct but closely related species of annual plants: a generalist that could cope well with both dry and moist conditions, and a specialist restricted to moist conditions. They demonstrated that offspring of the generalist species showed adaptive and plastic responses to drought, such as larger root systems, which were not found in the offspring of the species that was specialised to live exclusively in a moist environment.

Some forms of plasticity involve rapid responses to environmental challenges. Learning processes in all their different manifestations provide the obvious examples. The adaptive advantages of learning and memory confer additional capacity to recognise and avoid predation, to identify nutritional resources, to undertake sexual reproduction and so on. The evolution of learning mechanisms evidently began early in the history of life and may be uncovered by a comparative approach. The process of sensitisation to environmental conditions is found in organisms that are extremely ancient. Even this form of plasticity found in simple organisms requires the ability to categorise information provided by the environment. A process similar to behavioural imprinting in birds has been described in the nematode worm C. elegans (Remy and Hobert, 2005). The worms respond preferentially to food odours to which they have been exposed in early life. With such a capacity to distinguish between different types of stimuli in place, a plausible case can be made for the evolution of associative learning from sensitisation (Wells, 1967; Kandel and Schwartz, 1982).

\section{EVOLUTION OF CONDITIONAL PLASTICITY}

East African Acridoid grasshoppers deposit black melanin in their cuticle if the reflectance of the ground is low when they hatch out, as it would be after a savannah fire (Rowell, 1971). As a consequence of this mechanism, most grasshoppers are green in periods without fires and most are black in periods after fires when the savannah is blackened. The question therefore arises: under what conditions would the plasticity of the grasshopper evolve? If fires were infrequent and quickly followed by rain, it might be disadvantageous ever to be black. Conversely, if fires were frequent it might be advantageous to remain black at all times. In between these two extreme conditions, it would be highly advantageous to be capable of matching colour to the background. Whether or not the plasticity evolved would depend on whether individuals appeared that were capable of making the switch. If plasticity appeared and spread through the population, it might disappear again if the probability of fires dropped and an energetic cost was associated with the propensity to be plastic.

In the case of the freshwater crustacean, Daphnia pulex, Darwinian evolution has provided the young animals, still developing within the brood pouch of their mother, with the capacity to anticipate future conditions. The presence of a predatory midge in the water causes the young to form a defensive helmet and long tail spine. In the absence of the midge (or, more accurately, the chemical remains of Daphnia killed by the midge), the young do not develop the armour. The benefit of not doing so is that the non-helmeted females are able to devote their resources to making many more eggs in adulthood (Laforsch et al., 2006). The trade-off between forming a helmet or not is between present survival and future reproduction. In the presence of the predator, the balance swings towards devoting resources to improving the chances of survival, and in the absence of the predator the balance swings the other way towards producing more offspring. The maintenance of the capacity for such flexibility will depend on historical conditions. If predators had always been present and the capacity for changing the course of development carried a cost, this capacity would almost certainly have been lost. Conversely, it would almost certainly have been lost if predators that could be deterred by armour were never present.

In the Pennsylvanian meadow, vole coat thickness in the offspring is dependent on whether the mother experiences lengthening or shortening periods of daylight during pregnancy (Lee and Zucker, 1988). The mechanism is plausibly an evolved adaptation arising from correlated seasonal changes in temperature. Those mothers that did not signal the future conditions of the environment to their unborn offspring would have had a lower reproductive success than those mothers that did. Correspondingly, those offspring that failed to respond to the maternal cue would have been less likely to survive after birth than the responsive ones.

Where the cue is regular, such as seasonal change, it will have high fidelity. Selecting an appropriate developmental trajectory in response to the cue carries little risk and much advantage. When the cue reliability is less than perfect, the evolutionary benefit of a plastic response to environmental conditions must be greater than the cost of producing an inappropriate phenotype (Moran, 1992; Lachmann and Jablonka, 1996; Sultan and Spencer, 2002).

The delay between the detection of an inductive cue and the full expression of the phenotype is sometimes lengthy, as in the human case. A complex body cannot be built in a trice and adaptations to particular environmental conditions are often complex. This lag explains, in part, why a phenotype-once developed-cannot be readily changed and a mismatch of phenotype to environment can therefore arise if the forecast of local conditions proves incorrect. A further conceptual issue concerns the optimal time lag between detecting a cue that predicts a given set of environmental conditions and the phenotypic response to that cue. A hasty response might mean that conditions could change again before the adaptation becomes relevant. Left too late, and the capacity for plastic change might be exhausted or the adaptation may not be developed in time to be effective.

Conditional plasticity may confer the potential to cope with a wider range of environments than would otherwise be possible, and also to sustain fitness when environmental conditions fluctuate, particularly when the environment changes relatively slowly. When environments remain constant over long periods of time, the benefits of developmental plasticity are lost. The likelihood of loss would become greater if the underlying mechanisms of developmental plasticity were energetically costly to maintain.

\section{PLASTICITY AND EVOLUTION}

A central question in considering evolutionary change driven by plasticity is whether the transmitted epigenetic markers could facilitate genomic change (Johnson and Tricker, 2010). Many authors have argued that the plasticity of epigenetic processes provides a substrate of phenotypic variation on which Darwinian evolution can act (Pigliucci, 2001, West-Eberhard, 2003, Moczek et al., 2011, Moczek, 2012, Noble et al., 2014). Giving a central role to development in evolutionary processes has prompted researchers to wonder whether, and how, developmental systems fashion evolutionary outcomes. In most experimental studies, the environmental stimulus producing an epigenetic change is only applied in one generation. This might be enough since work on yeast (Saccharomyces cerevisiae) suggests that an 
environmental challenge can permanently alter regulation of genes (Braun and David, 2011). In natural conditions, the environmental cues that induce epigenetic change may be recurrent and repeat what has happened in previous generations. This recurring effect might stabilise the phenotype until genomic reorganisation has occurred (Jablonka and Raz, 2009; Bateson and Gluckman, 2011). Occasionally, DNA silencing may be stable as, for example, in the plant Linaria (Cubas et al., 1999), in which the epigenetically induced phenotype does not change from one generation to the next. Alternatively, the induced epigenetic changes that mediate adaptive plasticity might have biased the sites of subsequent mutation (Jablonka and Lamb, 1995; Bateson and Gluckman, 2011; Bateson, 2012). Variation at these sites may throw up phenotypes, some of which are adaptive and subject to Darwinian evolution. This is one way that plasticity might lead to evolutionary change.

Other ways in which an organism's activity and plasticity could initiate Darwinian evolution have intrigued many authors (Hardy, 1965; Bateson, 1988; Gottlieb, 1992; Gilbert and Epel, 2009; Pfennig et al., 2010; Pigliucci and Müller, 2010; Popper, unpublished and cited in Niemann 2014). Organisms and proto-organisms were arguably immobile in the initial stages of biological evolution. However, as they evolved, they would soon have become active. Although migration can be highly adaptive, the possibility of movement into a novel environment raises a key conceptual point in understanding how plasticity and behaviour can drive evolutionary change. Development depends on the constancy of many genetic and environmental conditions. If any of these conditions changes, as can happen to environmental conditions when organisms are mobile, the characteristics of the organism can also change. High mobility by organisms would have frequently placed them in conditions that revealed heritable variation not previously apparent in the population. By their mobility, in the case of animals, or facility to disperse in the case of plants, organisms would have exposed themselves to new conditions that might reveal heritable variability, thereby opening up possibilities for evolutionary changes that would not otherwise have taken place. A striking example of what can happen when an animal is mobile has been provided by the work on the three-spined stickleback (Gasterosteus aculeatus) moving from a marine to a freshwater environment (Foster and Wund, 2011). The developmental break-out may provide radically new opportunities for those individuals equipped with the new phenotype (West-Eberhard, 2003). For that reason, behaviour, along with other forms of dispersion, was likely to be important in initiating evolutionary change. In addition, behavioural adaptability of the animals would have helped buffer them against extinction in new conditions.

West-Eberhard (2003) argued that, after developmental disruption, the reorganisation of the genome may be substantial. She suggested that major changes might evolve as the character in question became more variable; in other words, it became developmentally less robust or less canalised. The umbrella term that she used for all the heritable changes that might occur in the genetic regulation of development in response to environmental influences was 'genetic accommodation'. In a similar vein, Gerhard and Kirschner (2007) argued that variation in the phenotype could be facilitated in particular circumstances.

Since Darwin (1871) first proposed it, the role of choice in the evolution of descendants has been increasingly recognised (Bateson, 2014). The organism can also do a great deal to create an environment to which it is best suited (Lewontin, 1983). By leaving an impact on their physical and social environment, organisms may affect the evolution of their own descendants, quite apart from changing the conditions for themselves. Some of the impact is subtle, such as when a plant sheds its leaves that fall to the ground and change the characteristics of the soil in which its own roots and those of its descendants grow. These ideas have been developed extensively and are now referred to as 'niche construction' (Odling-Smee et al., 2003; Laland et al., 2014). One example is provided by the two species of beavers (Castor canadensis and Castor fiber) that change their environment by building dams and creating lakes for themselves. This activity, it is argued, sets up conditions that affected the subsequent evolution of the ancestral beavers' descendants. The conjecture is that the artificially created aquatic environment led the beavers to evolve adaptations such as webbed feet that facilitated swimming. The hypothesis is plausible because in the suborder of rodents, the Castorimorpha, the two extant species of beaver are grouped with the true gophers and kangaroo rats, neither of which has webbed feet.

The adaptability of the organism is also likely to have had an important role in initiating evolutionary change, often referred to as the Baldwin effect. Baldwin (1896) published his ideas in the same year as Osborn (1896) and Lloyd Morgan (1896). All three were preceded by Spalding (1873) and for that reason I prefer to refer to the hypothesis as the 'adaptability driver' of evolution (Bateson, 2006). The general point is that if a group of organisms respond adaptively to a change in environmental conditions, the modification will recur generation after generation in the changed conditions, but the modification will not be inherited. However, any variation in the ease of expression of the modified character that is owing to genetic differences is liable to act in favour of those individuals that express the character most readily. As a consequence, an inherited predisposition to express the modifications in question will tend to evolve. The longer the evolutionary process continues, the more marked will be such a predisposition. Empirical support for this proposal has been growing in recent years (for example, Badyaev, 2009).

The effect of plasticity on evolution is likely to have become increasingly powerful as animals, in particular, become more complex. When such complexity entailed a greater ability to discriminate between different features of the environment or a greater ability to manipulate the environment, the organism would benefit and would be more likely to survive and reproduce in the face of multiple challenges during its lifetime. Plasticity would promote much more rapid genetic evolution of complex sets of adaptive systems than can be accomplished by mutation alone. Theoretical studies have indicated how crucial plasticity could be in such an evolutionary process (for example, Beltman et al., 2004; Lande, 2009; Chevin and Lande, 2011; Dukas, 2013). In general, an ability to cope with complex environmental challenges by means of plasticity opens up ecological niches previously unavailable to the organism. This would inevitably lead to the subsequent evolution of morphological, physiological and biochemical adaptations to those niches and the likelihood of speciation (Wyles et al., 1983; Pfennig and McGee, 2010). Where an environmental challenge involved greater processing capacity by the brain, this organ too would be expected to evolve with greater rapidity. On the assumption that the larger brain relative to body size ensures greater learning capacity, the rate of evolution should correlate positively with the relative brain size. The expectation is supported by the correlations found between behavioural innovation and brain size reported for birds (Sol et al., 2005) and primates (Reader and Laland, 2003). The characteristics of an organism may be such that they constrain the course of subsequent evolution or they may facilitate a particular form of evolutionary change. The organism's mobility, its choices, its construction of a niche for itself and its adaptability are all likely to have had important roles in such change. 


\section{CONCLUSION}

Individuals differ for a variety of reasons, some genetic and some stochastic. Undoubtedly their plasticity, which comes in many forms, also contributes greatly to the variation commonly found in most populations. The processes involved in plasticity can operate at many different levels, ranging from the molecular to the behavioural, some involving adaptability to what may be novel challenges and some responding conditionally to local circumstances. Phenotypic variation can be triggered in a variety of ways, some mediated through the parent's phenotype. Sometimes phenotypic variation arises because the environment triggers a developmental response that is appropriate to those ecological conditions. Sometimes the organism 'makes the best of a bad job' in suboptimal conditions. Sometimes the buffering processes of development may not cope with what has been thrown at the organism, and a bizarre phenotype is generated. Whatever the adaptedness of the phenotype, each of these effects demonstrate how a given genotype will express itself differently in different environmental conditions.

The current interest in plasticity has led to a rapid expansion of developmental studies. It has also led to a re-evaluation of ancient dichotomies of the nature/nurture variety. Plastic processes are usually, if not always, well regulated and the regulation is usually, if not always, robust. Moreover, the outcome of a plastic process may be highly robust. Consequently, attempts to divide those phenotypic features of an organism into those that are plastic and those that are robust is misleading and misrepresents what happens during development. The theories of biological evolution have been also reinvigorated by the work on plasticity. The combination of developmental and behavioural biology, physiology, ecology and evolutionary biology has shown how important the active roles of the organism are in the evolution of its descendants.

\section{CONFLICT OF INTEREST}

The author declares no conflict of interest.

\section{ACKNOWLEDGEMENTS}

I thank three anonymous referees who took more than the usual amount of trouble when commenting on this article.

Anway MD, Cupp AS, Uzumcu M, Skinner MK (2005). Epigenetic transgenerational actions of endocrine disruptors and male fertility. Science 308: 1466-1469.

Badyaev AV (2009). Evolutionary significance of phenotypic accommodation in novel envirinment: an empirical test of the Baldwin effect. Philos Trans $R$ Soc Lond Ser B 364: 1125-1141.

Baldwin JM (1896). A new factor in evolution. Am Naturalist 30: 536-553.

Baldwin JM (1902). Development and Evolution. Macmillan: London, UK.

Bateson PPG (1966). The characteristics and context of imprinting. Biol Rev 4I: 177-220.

Bateson P (1983). Optimal outbreeding. In: Bateson P (ed). Mate Choice. Cambridge University Press: Cambridge, UK. pp 257-277.

Bateson P (1988). The active role of behaviour in evolution. In: Ho M-W, Fox S (eds). Process and Metaphors in Evolution. Wiley: Chichester, UK. pp 191-207.

Bateson P (2001). Fetal experience and good adult design. Int J Epidemiol 30: 928-934.

Bateson P (2006). The adaptability driver: links between behaviour and evolution. Biol Theory 1: 342-345.

Bateson P (2012). The impact of the organism on its descendants. Genet Res Int 2012 : 640612.

Bateson P (2014). New thinking about biological evolution. Biol J Linn Soc 112: 268-275.

Bateson P, Gluckman P (2011). Plasticity, Robustness, Development and Evolution. Cambridge University Press: Cambridge, UK

Bateson P, Gluckman P, Hanson MA (2014). The biology of developmental plasticity and the Predictive Adaptive Response hypothesis. J Physiol 592: 2357-2368.

Bateson P, Martin P (1999). Design for a Life: How Behaviour Develops. Cape: London, UK.

Beltman JB, Haccou P, ten Cate C (2004). Learning and colonization of new niches: a first step towards speciation. Evolution 58: 35-46.
Bolhuis JJ (1991). Mechanisms of avian imprinting: a review. Biol Rev 66: 303-345.

Braun E, David L (2011). The role of cellular plasticity in the evolution of regulatory novelty. In: Gissis SB, Jablonka E (eds). Transformations of Lamarckism: From Subtle Fluids to Molecular Biology. MIT Press: Cambridge, MA, USA. pp 181-191.

Carey N (2012). The Epigenetics Revolution. Icon: London, UK.

Chali D, Enquselassie F, Gesese M (1998). A case-control study on determinants of rickets. Ethiop Med J 36: 227-234.

Chevin L-M, Lande R (2011). Adaptation to marginal habitats by evolution of increased phenotypic plasticity. J Evol Biol 24: 1462-1476.

Cortijo S, Wardenaar R, Colomé-Tatché M, Gilly A, Etcheverry M, Labadie K et al. (2014). Mapping the epigenetic basis of complex traits. Science 343: 1145-1148.

Cubas P, Vincent C, Coen E (1999). An epigenetic mutation responsible for natural variation in floral symmetry. Nature 401: 157-161.

Danchin E, Charmantier A, Champagne FA, Mesoudi A, Pujal B, Blanchet S (2011). Beyond DNA: integrating inclusive inheritance into an extended theory of evolution. Nat Rev Genet 12: 475-486.

Darwin C (1871). The Descent of Man, and Selection in Relation to Sex. Murray: London, UK.

Dukas R (2013). Effects of learning on evolution:robustness, innovation and speciation. Anim Behav 85: 1023-1030.

Erwin DH (2008). Macroevolution of ecosystem engineering, niche construction and diversity. Trends Ecol Evol 23: 304-310.

Foster SA, Sih A (2013). Behavioural plasticity and evolution. Anim Behav 85: 1003

Foster SA, Wund MA (2011). Epigenetic contributions to adaptive radiation: insights from threespined stickleback. In: Hallgrimsson B, Hall BK (eds). Epigenetics: Linking Genotype and Phenotype. University of California: Berkeley CA, USA. pp 317-336.

Gerhart JC, Kirschner MW (2007). The theory of facilitated variation. Proc Natl Acad Sci USA 104: 8582-8589.

Gilbert SF, Epel D (2009). Ecological Developomental Biology: Integrating Epigenetics, Medicine and Evolution. Sinauer: Sunderland, MA, USA.

Gissis SB, Jablonka E (2011). Transformations of Lamarckism: From Subtle Fluids to Molecular Biology. MIT Press: Cambridge, MA, USA.

Gluckman P, Hanson M (2004). The Fetal Matrix. Cambridge University Press: Cambridge, UK.

Gluckman P, Hanson M (2006). Mismatch: Why Our World No Longer Fits Our Bodies. Oxford University Press: Oxford, UK.

Gluckman PD, Hanson MA, Buklijas T (2010). A conceptual framework for the developmental origins of health and disease. J Dev Origin Health Dis 1: 6-18.

Gluckman PD, Hanson MA, Spencer HG, Bateson P (2005). Environmental influences during development and their later consequences for health and disease: implications for the interpretation of empirical studies. Proc $R$ Soc Ser B 272: 671-677.

Gollin ES (ed) (1981). Developmental Plasticity: Behavioral and Biological Aspects of Variations in Development. Academic Press: New York, NY, USA.

Gottlieb G (1992). Individual Development and Evolution. Oxford University Press: New York, NY, USA.

Hardy A (1965). The Living Stream. Collins: London, UK.

Heisenberg M (2013). Action selection. In: Menzel R, Benjamin PR (eds). Invertebrate Learning and Memory. Academic Press: London, UK.

Horn G, Rose SPR, Bateson PPG (1973). Experience and plasticity in the central nervous system. Science I8I: 506-514.

Jablonka E, Lamb MJ (1995). Epigenetic Inheritance and Evolution. Oxford University Press: Oxford, UK

Jablonka E, Lamb MJ (2005). Evolution in Four Dimensions. MIT Press: Cambridge, MA, USA.

Jablonka E, Lamb MJ (2010). Transgenerational epigenetic inheritance. In: Pigliucci M, Müller GB (eds). Evolution-The Extended Synthesis. MIT Press: Cambridge, MA, USA. pp 137-174.

Jablonka E, Raz G (2009). Transgenerational epigenetic inheritance: prevalence, mechanisms, and implications for the study of heredity and evolution. Q Rev Bio/ 84: 131-176.

Jahoor F, Badaloo A, Reid M, Forrester T (2008). Unique metabolic characteristics of the major syndromes of severe childhood malnutrition. In: Forrester T, Picou D, Walker S (eds). The Tropical Metabolism Research Unit the University of the West Indies Jamaica, 1956-2006: The House that John Built. Randle: Kingston, ON, Canada. pp 25-60.

Jirtle RL, Skinner MK (2007). Environmental epigenomics and disease susceptibility. Nat Rev Genet 8: 253-262.

Johannes F, Porcher E, Teixeira FK, Saliba-Colombani V, Simon M, Agier N et al. (2009). Assessing the impact of transgenerational epigenetic variation on complex traits. PLoS Genetics 5, e1000530.

Johnson LJ, Tricker PJ (2010). Epigenomic plasticity within populations: its evolutionary significance and potential. Heredity 195: 113-121.

Jones AP, Friedman MI (1982). Obesity and adipocyte abnormalities in offspring of rats undernourished during pregnancy. Science 215: 1518-1519.

Kandel ER, Schwartz JH (1982). Molecular biology of learning : modulation of transmitter release. Science 218: 433-443.

Kappeler PM, Barrett L, Blumstein DT, Clutton-Brock TH (2013). Constraints and flexibility in mammmalian social behaviour: introduction and synthesis. Philos Trans $R$ Soc Ser $B$ 368: 1-10.

Kruuk LEB, Clutton-Brock TH, Rose KE, Guinness FE (1999). Early determinants of lifetime reproductive success differ between the sexes in red deer. Proc $R$ Soc Lond Ser B 266: 1655-1661. 
Lachman M, Jablonka E (1996). The inheritance of phenotypes: an adaptation to fluctuating environments. J Theoret Biol 181: 1-9.

Laforsch C, Beccara L, Tollrian R (2006). Inducible defenses: the relevance of chemical alarm cues in Daphnia. Limnol Oceanogr 51: 1466-1472.

Laland K, Odling-Smee J, Turner S (2014). The role of internal and external constructive processes in evolution. J Physiol 592: 2413-2422.

Lande R (2009). Adaptation to an extraordinary environment by evolution of phenotypic plasticity and genetic assimilation. J Evol Biol 22: 1435-1446.

Lee TM, Zucker I (1988). Vole infant development is influences perinatally by maternal photoperiodic history. Am J Physiol 255: R831-R838.

Lerner R (1984). On the Nature of Human Plasticity. Cambridge University Press: Cambridge, UK.

Lewontin RC (1983). Gene, organism and environment. In: Bendall DS (ed) Evolution from Molecules to Men. Cambridge University Press: Cambridge, UK. pp 273-285.

Lloyd Morgan C (1896). On modification and variation. Science 4: 733-740.

Lorenz K (1935). Der Kumpan in der Umwelt des Vogels. J Ornithol 83: 289-413.

Marler P, Slabberkoorn H (2004). Nature's Music: the Science of Birdsong. Elsevier/ Academic Press: San Diego, CA, USA.

Nieman H-J (2014). Karl Popper and the Two New Secrets of Life. Mohr Siebeck: Tübingen, Germany.

McMillen IC, Robinson JS (2005). Developmental origins of the metabolic syndrome: prediction, plasticity, and programming. Physiol Rev 85: 571-633.

Meysman FJR, Middelburg JJ, Help CHR (2006). Bioturbation: a fresh look at Darwin's last idea. Trends Ecol Evol 21: 688-695.

Miles JL, Landon J, Davison M, Krageloh CU, Thompson NM, Triggs CM et al. (2009). Prenatally undernourished rats show increased preference for wheel running $\mathrm{v}$. lever pressing for food in a choice task. Br J Nutr 101: 902-908.

Moczek AP (2012). The nature of nurture and the future of evodevo: toward a theory of developmental evolution. Integr Compar Biol 52: 108-119.

Moczek AP, Sultan S, Foster S, Ledón-Rettig C, Dworkin I, Nijhout HF et al. (2011). The role of developmental plasticity in evolutionary innovation. Proc $R$ Soc Ser $B$ 278: 2714-2723.

Moran NA (1992). The evolutionary maintenance of alternative phenotypes. Amer Nat 139: 249-278.

Mousseau TA, Fox CW (1998). Maternal Effects as Adaptations. Oxford University Press: New York, NY, USA.

Noble D, Jablonka E, Joyner M, Muller G, Omholt SW (2014). Evolution evolves: physiology returns to centre stage. J Physiol 592: 2237-2244.

Odling-Smee FJ, Laland KN, Feldman MW (2003). Niche Construction: The Neglected Process of Evolution. Princeton University Press: Princeton, NJ, USA.

Osborn HF. (1896). Ontogenic and phylogenic variation. Science 4: 786-789.

Pfennig DW, McGee M (2010). Resource polyphenism increases species richness: a test of the hypothesis. Philos Trans R Soc Ser B 365: 577-591.

Pfennig DW, Wund MA, Snell-Rood EC, Cruickshank T, Schlichting CD, Moczek AP (2010). Phenotypic plasticity's impacts on diversification and speciation. Trends Ecol Evol 25 459-487.

Piersma T, van Gils JA (2010). The Flexible Phenotype: A Body-Centered Integration of Ecology, Physiology and Behaviour. Oxford University Press: Oxford, UK.

Pigliucci M (2001). Phenotypic Plasticity: Beyond Nature and Nurture. Johns Hopkins University Press: Baltinore, MD, USA.

Pigliucci M, Müller GB (2010). Evolution: The Extended Synthesis. MIT Press: Cambridge, MA, USA.

Rassoulzadegan M (2011). An evolutionary role for RNA-mediated epigenetic variation? In: Gissis SB, Jablonka E (eds). Transformation of Lamarckism: From Subtle Fluids to Molecular Biology. MIT Press: Cambridge, MA, USA. pp 227-235.

Rauschecker JP, Marler P (1987). Imprinting and Cortical Plasticity. Wiley: New York, NY, USA.

Reader SM, Laland KN (2003). Animal Innovation. Oxford University Press: Oxford, UK.
Rechavi O (2014). Guest list or black list: heritable small RNAs as immunogenic memories. Trends Cell Biol 24: 212-220.

Remy JJ, Hobert 0 (2005). An interneuronal chemoreceptor required for olfactory imprinting in C. elegans. Science 309: 787-790.

Rowell CHF (1971). The variable coloration of the Acridoid grasshoppers. Adv Insect Physiol 8: 145-198.

Saastamoinen M, van der Sterren D, Vastenhout N, Zwaan BJ, Brakefield PM (2010) Predictive adaptive responses: condition-dependent impact of adult nutrition and flight in the tropical butterfly Bicyclus anynana. Am Naturalist 176: 686-698.

Sandman CA, Davis EP, Buss C, Glynn LM (2012). Exposure to prenatal psychobiological stress exerts programming influences on the mother and her fetus. Neuroendocrinology 95: 7-21.

Shettleworth SJ (2010). Cognition, Evolution and Behavior, 2nd edn. Oxford University Press: New York, NY, USA

Skinner BF (1984). Selection by consequences. Behav Brain Sci 7: 477-481B.

Slijper EJ (1942). Biologic-anatomical investigations on the bipedal gait and upright posture in mammals, with s pecial reference to a little goat, born without forelegs. I and II. Proc Kon Ned Akad Wetensch 45: 407-415.

Sloboda DM, Hart R, Doherty DA, Pennell CE, Hickey M (2007). Age at menarche: influences of prenatal and postnatal growth. J Clin Endocrinol Metab 92: 46-50.

Snell-Rood EC (2012). Selective processes in development: Implications for the costs and benefits of phenotypic plasticity. Integr Compar Biol 52: 31-42.

Snell-Rood EC (2013). An overview of the evolutioary causes and consequences of behavioural plasticity. Anim Behav 85: 1004-1011.

Sol D, Duncan RP, Blackburn TM, Cassey P, Lefebvre L (2005). Big brains, enhanced cognition, and response of birds to novel environments. Proc Natl Acad Sci USA 102: 5460-5465.

Spalding DA (1873). Instinct with original observations on young animals. Macmillan's Mag 27: 282-293.

Spector T (2012). Identically Different: Why You Can Change Your Genes. Weidenfeld \& Nicolson: London, UK.

Stouder C, Paoloni-Giacobino A (2010). Transgenerational effects of the endocrine disruptor vinclozolin on the methylation pattern of imprinted genes in the mouse sperm. Reproduction 139: 373-379.

Sultan SE, Spencer HG (2002). Metapopulation structure favors plasticity over local adaptation. Amer Nat 160: 271-283.

Thorpe WH (1956). Learning and Instinct in Animals. Methuen: London, UK.

van Buskirk J, Steiner UK (2009). The fitness costs of developmental canalization and plasticity. J Evol Biol 22: 852-860.

Vickers MH, Breier B, McCarthy D, Gluckman P (2003). Sedentary behavior during postnatal life is determined by the prenatal environment and exacerbated by postnatal hypercaloric nutrition. Am J Physiol Regul Integr Compar Physiol 285. R271-R273.

Vickers MH, Breier BH, Cutfield WS, Hofman PL, Gluckman PD (2000). Fetal origins of hyperphagia, obesity, and hypertension and postnatal amplification by hypercaloric nutrition. Am J Physiol 279: E83-E87.

von Moltke HJ, Olbing H (1989). Die Ausbildungs- und Berufssituation contergangeschadigter junger Erwachsener. Rehabilitation 28: 78-82.

Waddington CH (1957). The Strategy of the Genes. Allen \& Unwin: London, UK.

Wagner GP, Pavlicev M, Cheverud JM (2007). The road to modularity. Nat Rev Genet 8: 921-931

Wells MJ (1967). Sensitization and the evolution of associative learning. In: Salanki J (ed). Symposium on Neurobiology of Invertebrates. Plenum: New York. pp 391-411.

West-Eberhard MJ (2003). Developmental Plasticity and Evolution. Oxford University Press: New York, NY, USA.

Wyles JS, Kunkel JG, Wilson AC (1983). Birds, behavior, and anatomical evolution. Proc Natl Acad Sci USA 80: 4394-4397.

Wund MA. (2012). Assessing the impacts of phenotypic plasticity on evolution. Intergr Compar Biol 52: 5-15. 